\title{
Inhibition of Multidrug Resistance Proteins by MK 571 Enhances Bladder, Prostate, and Urethra Relaxation through cAMP or cGMP Accumulation
}

\author{
Gabriela Maria Bertollotto, Mariana Gonçalves de Oliveira, Eduardo Costa Alexandre, \\ Fabiano Beraldi Calmasini, Gabriela Reolon Passos, Edson Antunes, \\ and (D) Fabiola Zakia Mónica \\ Department of Pharmacology, Faculty of Medical Sciences, University of Campinas, Campinas, São Paulo, Brazil
}

Received May 2, 2018; accepted August 3, 2018

\begin{abstract}
The biologic effect of CAMP and cGMP is terminated by phosphodiesterases and multidrug resistance proteins MRP4 and MRP5, which pump cyclic nucleotides out of the cell. Therefore, this study aimed to characterize the role of MRP inhibitor, MK 571 (3-[[[3-[(1E)-2-(7-chloro-2-quinolinyl)ethenyl]phenyl][[3(dimethylamino)-3-oxopropyl]thio]methyl]thio]propanoic acid), in the bladder, prostate, and urethra of male mice by means of functional assays, protein expression, and cyclic nucleotide quantification. The cumulative addition of MK $571(1-30 \mu \mathrm{M})$ produced only small relaxation responses (approximately $25 \%$ ) in all studied tissues. In the bladder, isoprenaline/fenoterol and forskolin concentration-dependently relaxed and MK $571(20 \mu \mathrm{M})$ increased the maximal response values by $37 \%$ and $24 \%$, respectively. When MK 571 was coincubated with fenoterol or forskolin, intracellular levels of CAMP and protein expression of phospho-vasodilatorstimulated phosphoprotein ( $p$-VASP) Ser157 were significantly
\end{abstract}

greater compared with bladders stimulated with fenoterol or forskolin alone. In the prostate and urethra, sodium nitroprusside concentration-dependently relaxed and MK $571(20 \mu \mathrm{M})$ significantly increased relaxation responses by $70 \%$ and $56 \%$, respectively, accompanied by greater intracellular levels of cGMP and protein expression of p-VASP Ser239 in the prostate. Tadalafil and BAY 41-2272 (5-cyclopropyl-2-[1-[(2-fluorophenyl)methyl]$1 H$-pyrazolo[3,4-b]pyridin-3-yl]-4-pyrimidinamine) also relaxed the prostate and urethra, respectively, and MK 571 markedly enhanced this response. The stable analog of cGMP (8-Br-cGMP) induced concentration-dependent relaxation responses in the prostate and urethra, and MK 571 significantly increased the relaxation response. In conclusion, to our knowledge, this is the first study to show that efflux transporters are physiologically active in the bladder, prostate, and urethra to control intracellular levels of cAMP or cGMP.

\section{Introduction}

cAMP and cGMP are key second messengers that regulate a variety of physiologic functions, including vascular and nonvascular smooth muscle relaxation (Calmasini et al., 2017; Tanaka et al., 2017), natriuresis (Ahloulay et al., 1996), cell proliferation (Garg and Hassid, 1989), platelet function (Mellion et al., 1981), sperm motility (Yunes et al., 2005), and fluid and ion secretion (Vaandrager et al., 2000).

Intracellular levels of cAMP or cGMP are controlled by their rate of formation through the activation of adenylate cyclase (Chan and Lutfy, 2006) and soluble guanylate cyclase (sGC) or particulate guanylate cyclase (Pyriochou and Papapetropoulos, 2005), respectively and their rate of hydrolysis by cyclic nucleotide

This work was supported by the Fundação de Amparo à Pesquisa do Estado de São Paulo [Grant 2017/15175-1] and the Fundo de Apoio ao Ensino, à Pesquisa e Extensão [Grant 0122/2017].

https://doi.org/10.1124/jpet.118.250076. phosphodiesterase (PDE) activities (Werkstrom et al., 2009). Levels of cAMP and cGMP may also be controlled nonenzymatically by multidrug resistance proteins MRP4, MRP5, and MRP8, which pump cAMP and/or cGMP out of the cell (Sager and Ravna, 2009). The biologic effects of cAMP and cGMP are exerted through the activation of protein kinases A and G (PKA and PKG, respectively), cyclic nucleotide-gate ion channels, and activation or inhibition of PDEs (Uckert et al., 2006).

Subtypes MRP4 and MRP5 are considered the main transporters responsible for controlling cyclic nucleotide levels (Kruh and Belinsky, 2003; Wen et al., 2015). Although both subtypes have affinity for cAMP and cGMP (Jedlitschky et al., 2000; Chen et al., 2001), the majority of studies have focused on the role of MRP4, which also transports naturally occurring metabolites (e.g., glutathione, glucoronate and sulfate conjugates, and prostanoids; Reid et al., 2003; Ritter et al., 2005; Rius et al., 2005) as well as antiviral and antineoplastic agents (mainly nucleoside analogs; Köck et al., 2007). Efflux of cyclic

ABBREVIATIONS: BAY 41-2272, 5-cyclopropyl-2-[1-[(2-fluorophenyl)methyl]-1H-pyrazolo[3,4-b]pyridin-3-yl]-4-pyrimidinamine; BAY 58-2667, 4[[(4-carboxybutyl)[2-[2-[[4-(2-phenylethyl)phenyl]methoxy]phenyl]ethyl]amino]methyl]benzoic acid hydrochloride; LUT, lower urinary tract; MK 571, 3-[[[3-[(1E)-2-(7-chloro-2-quinolinyl)ethenyl]phenyl][[3-(dimethylamino)-3-oxopropyl]thio]methyl]thio]propanoic acid; MRP, multidrug resistance protein; NO, nitric oxide; p-VASP, phospho-vasodilator-stimulated phosphoprotein; PDE, phosphodiesterase; PKA, protein kinase A; PKG, protein kinase G; sGC, soluble guanylate cyclase. 
nucleotides through MRP4 has been seen in the gut (Moon et al., 2015), vessels (Sassi et al., 2008; Krawutschke et al., 2015), and blood cells such as erythrocytes (Wu et al., 2005) and platelets (Borgognone and Pulcinelli, 2012; Decouture et al., 2015). In addition, MRP4 was found in urogenital tract organs such as the prostate, seminal vesicle, and bladder (Rius et al., 2005). MRP4 was coexpressed with cyclooxygenase type 2 and the microssomal prostaglandin $\mathrm{E}$ synthase on epithelial cells from the seminal vesicle. MRP4 was able to export prostaglansin $\mathrm{E} 2$, prostaglandin $\mathrm{F} 2 \alpha$, and thromboxane B2 in membrane vesicles from MRP4-overexpressing cells, thus suggesting that MRP4 might be involved in prostanoid transport (Rius et al., 2005).

The tonus of smooth muscle from the urogenital tract organs involves the network between substances released from central and peripheral nervous systems and from the mucosa (Fraser and Chancellor, 2003; White et al., 2013; Merrill et al., 2016). cAMP and cGMP are considered the main inhibitory second messengers to regulate smooth muscle relaxation of the bladder, prostate, urethra, and corpus cavernosum (Rahnama'i et al., 2013; Mónica and Antunes, 2018).

In the bladder, the importance of the cAMP signaling pathway in relaxing and improving cystometric parameters in patients with lower urinary tract (LUT) symptoms (Qiu et al., 2002) is well explored and led to the development of the $\beta 3$-adrenoceptor, mirabegron (Yamaguchi et al., 2014). In the human prostate, expression of cAMP and cGMP PDEs was shown at the protein and gene levels (Zhao et al., 2011; Giuliano et al., 2013). Localization of PDE4 and PDE5, which preferentially hydrolyze cAMP and cGMP, respectively, was observed on the stromal and glandular areas of the transition zone (Uckert et al., 2005). Functional assays showed that inhibition of PDE4 and PDE5 by rolipram and sildenafil, respectively, induced relaxation in precontracted tissues (Kedia et al., 2009). In 2011, tadalafil, a PDE5 inhibitor, was the first drug approved by the Food and Drug Administration (FDA) and European Medicine Agency (EMA) for use in treating patients with LUT symptoms secondary to benign prostatic hyperplasia ( $\mathrm{McVary}$ et al., 2007), thus reinforcing the clinical relevance of targeting the cGMP pathway to induce prostate relaxation in patients with benign prostatic hyperplasia. In the urethra, both cAMP and cGMP lead to smooth muscle relaxation, although the role of the nitric oxide (NO)/cGMP pathway under pathologic conditions is better studied (Sancho et al., 2014).

Because we proposed to evaluate whether inhibition of MRP4 and MRP5 synergizes with substances that increase levels of cAMP or cGMP, this study aimed to verify the role of MK 571 (3-[[[3-[(1E)-2-(7-chloro-2-quinolinyl)ethenyl]phenyl] [[3-(dimethylamino)-3-oxopropyl]thio]methyl]thio]propanoic acid), a nonselective MRP4 and MRP5 inhibitor, by means of functional assays, protein expression, and cyclic nucleotide quantification in the bladder, prostate, and urethra of mice.

\section{Materials and Methods}

Animals. All animal procedures and experimental protocols were carried out according to the Ethical Principles in Animal Research adopted by the Brazilian College for Animal Experimentation and approved by the University of Campinas Institutional Committee for Ethics in Animal Research (protocol number 4201-1). Twelve-week-old male C57BL6/J mice (Central Animal House Services, University of
Campinas, Campinas, Brazil) were housed three per cage on a 12-hour/12-hour light/dark cycle.

Tissue Isolation. Strips from the detrusor and prostate and rings from the urethra were obtained and mounted in $10 \mathrm{ml}$ (bladder) or $4 \mathrm{ml}$ (prostate and urethra) organ bath containing Krebs-Henseleit solution composed of $117 \mathrm{mM} \mathrm{NaCl}, 4.7 \mathrm{mM} \mathrm{KCl}, 2.5 \mathrm{mM} \mathrm{CaCl}_{2}, 1.2 \mathrm{mM}$ $\mathrm{MgSO}_{4}, 1.2 \mathrm{mM} \mathrm{KH} \mathrm{PO}_{4}, 25 \mathrm{mM} \mathrm{NaHCO}$, and $5.5 \mathrm{mM}$ glucose continuously bubbled with a mixture of $95 \% \mathrm{O}_{2}$ and $5 \% \mathrm{CO}_{2}(\mathrm{pH} 7.4)$ at $37^{\circ} \mathrm{C}$. Changes in isometric force were recorded using a Power Laboratory system (version 7.2; ADInstruments, Sydney, Australia). Resting tension was adjusted to $5 \mathrm{mN}$ at the beginning of the experiments for all tissues. The equilibration period was 45 minutes; the bathing medium was changed every 15 minutes and the tension was adjusted, only when necessary (de Oliveira et al., 2016; Calmasini et al., 2017).

Functional Assays. First, concentration-response curves to MK $571(1-30 \mu \mathrm{M})$ were determined in the bladder, prostate, and urethra in tissues precontracted with carbachol (bladder) or phenylephrine (prostate and bladder). Second, concentration-response curves to several agonists that increase cAMP or cGMP were determined in the bladder, prostate, and urethra in the absence (control) and presence of MK 571 (20 $\mu \mathrm{M})$, which was incubated 30 minutes before. The protocols for each tissue were as follows: 1$)$ bladder: isoproterenol (0.001-100 $\mu \mathrm{M})$, fenoterol $(0.001-100 \mu \mathrm{M})$, forskolin $(0.001-100$ $\mu \mathrm{M})$, and BAY 58-2667 (4-[[(4-carboxybutyl)[2-[2-[[4-(2-phenylethyl) phenyl]methoxy]phenyl]ethyl] amino]methyl]benzoic acid hydrochloride) $(0.001-10 \mu \mathrm{M}) ; 2)$ prostate: sodium nitroprusside (0.001-100 $\mu \mathrm{M})$, tadalafil $(0.001-100 \mu \mathrm{M})$, 8-Br-cGMP $(0.001-100 \mu \mathrm{M})$, and forskolin (0.001-100 $\mu \mathrm{M})$; and 3) urethra: BAY 41-2272 (5-cyclopropyl2-[1-[(2-fluorophenyl)methyl]-1H-pyrazolo[3,4-b]pyridin-3-yl]-4pyrimidinamine) $(0.001-100 \mu \mathrm{M})$, sodium nitroprusside $(0.001-100 \mu \mathrm{M})$, 8-Br-cGMP (0.001-100 $\mu \mathrm{M})$, and forskolin $(0.001-100 \mu \mathrm{M})$. The bladder was precontracted with carbachol $(1 \mu \mathrm{M})$, whereas the prostate and urethra were precontracted with phenylephrine $(10 \mu \mathrm{M})$. Relaxation responses were calculated as the percentage of the maximal changes from the steady-state contraction produced in each tissue, and potency $\left(\mathrm{pEC}_{50}\right)$ and maximal response values $\left(E_{\max }\right)$ were determined.

Data Analysis of Functional Assays. Nonlinear regression analysis to determine the $\mathrm{pEC}_{50}$ was carried out using GraphPad Prism software (GraphPad Software Inc., San Diego, CA), with the constraint that $F=0$. All concentration-response data were evaluated for a fit to a logistics function in the following form:

$$
E=E_{\max } /([1+(10 c / 10 x) n]+F)
$$

where $E$ is the maximum response produced by agonists; $c$ is the logarithm of the $\mathrm{EC}_{50}$, the concentration of drug that produces a halfmaximal response; $x$ is the logarithm of the concentration of the drug; the exponential term, $n$, is a curve-fitting parameter that defines the slope of the concentration-response line; and $F$ is the response observed in the absence of added drug. $E_{\max }$ values are given in percentages. $\mathrm{EC}_{50}$ values are presented as the negative logarithm $\left(\mathrm{pEC}_{50}\right)$ and were calculated by fitting a concentration-response relationship to a sigmoidal model of the form log-concentration versus response using GraphPad Prism software.

Quantification of Intracellular Levels of cGMP and cAMP in the Bladder and Prostate. cGMP levels were determined in the prostate in unstimulated (basal) tissues and in tissues stimulated with sodium nitroprusside ( $1 \mu \mathrm{M}, 10$ minutes) or tadalafil $(10 \mu \mathrm{M}$, 10 minutes) alone or in combination with MK $571(20 \mu \mathrm{M})$ added 30 minutes prior. As for the cAMP quantification, bladders were stimulated with fenoterol ( $3 \mu \mathrm{M}, 10$ minutes) or forskolin $(100 \mu \mathrm{M}$, 10 minutes) in the absence and presence of MK $571(20 \mu \mathrm{M}, 30$ minutes). After the 10-minute stimulation period, tissues were quickly frozen in liquid nitrogen. The frozen tissues were pulverized and homogenized in trichloroacetic acid $[5 \%(\mathrm{w} / \mathrm{v})]$ and centrifuged for 10 minutes at $4^{\circ} \mathrm{C}$ at $1500 \mathrm{~g}$. The tracer, samples, and standards were 
A

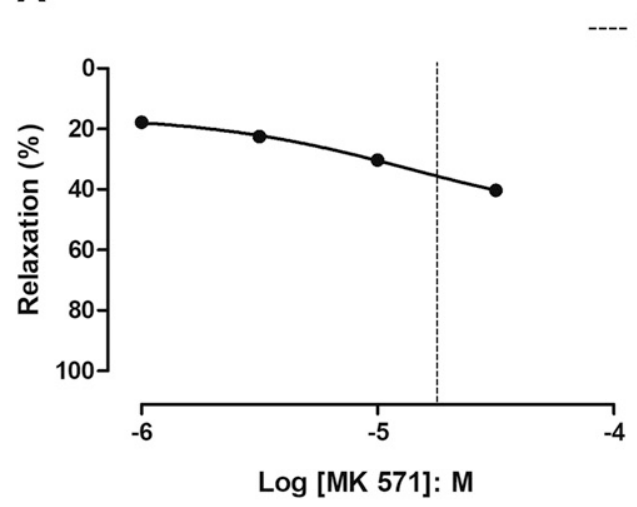

B

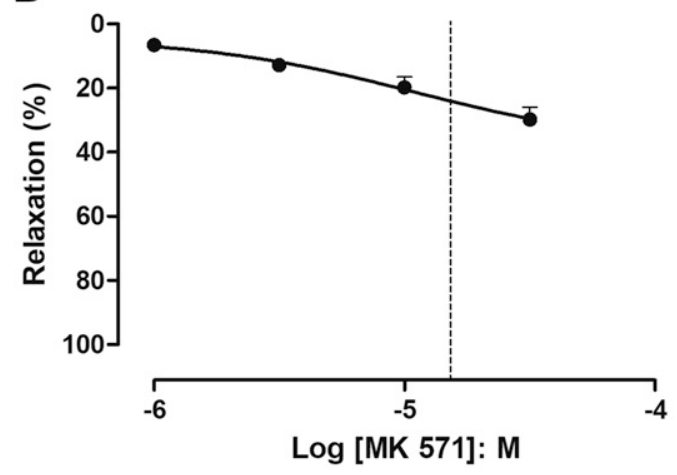

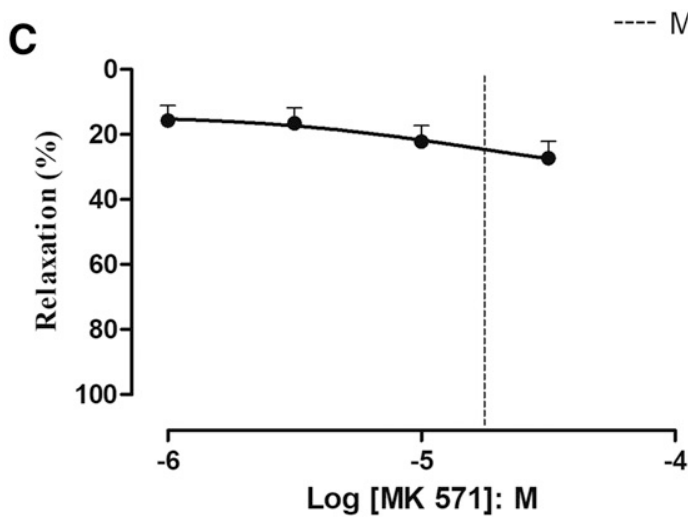

Fig. 1. (A-C) Concentration-response curves to MK $571(1-30 \mu \mathrm{M})$ in the isolated bladder (A), prostate (B), and urethra (C) from mice in tissues precontracted with carbachol $(1 \mu \mathrm{M})$ or phenylephrine $(10 \mu \mathrm{M})$. Data are the mean \pm S.E.M. $(n=4$ animals $)$.

prepared as described in the kit instructions (cAMP or cGMP EIA kit; Cayman Chemical, Ann Arbor, MI). The assays were performed in duplicate, and the data are expressed in picomoles per milliliter.

Protein Expression for Phospho-Vasodilator-Stimulated Phosphoproteins p-VASP Ser157 and p-VASP Ser239. To evaluate the expression of phospho-vasodilator-stimulated phosphoproteins p-VASP Ser157 and p-VASP Ser239 in the bladder and prostate, tissues were stimulated with fenoterol ( $3 \mu \mathrm{M}, 10$ minutes) or sodium nitroprusside ( $1 \mu \mathrm{M}, 10$ minutes), respectively, in the absence and presence of MK 571 (20 $\mu \mathrm{M}, 30$ minutes). Bladder and prostate tissues were then homogenized in SDS lysis buffer using a sonicator (model FB120; Fisher Scientific, Pittsburgh, PA) and centrifuged at $1500 \mathrm{~g}$ at $4^{\circ} \mathrm{C}$ for 20 minutes to remove insoluble material. Protein concentrations of the supernatants were determined by the Lowry assay, and an equal amount of protein from each sample $(70 \mu \mathrm{g})$ was treated with Laemmli buffer containing dithiothreitol $(100 \mathrm{mM})$. Samples were heated in boiling water for 5 minutes and resolved by SDS-PAGE (10\%). Proteins were separated by $10 \%$ polyacrylamide gels and then electrotransfered to nitrocellulose membrane, performed for 90 minutes at a fixed amperage ( $0.15 \mathrm{~mA}$ per membrane) in a semidry device (Bio-Rad, Irvine, CA). Nonspecific protein binding was reduced by preincubation in blocking buffer $(0.5 \%$ nonfat dried milk, $10 \mathrm{mM}$ Tris, $100 \mathrm{mM} \mathrm{NaCl}$, and $0.02 \%$ Tween 20). Anti-VASP Ser157 (rabbit, 1: 1000; Santa Cruz Biotechnology, Dallas, TX), anti-VASP Ser239 (rabbit, 1:1000, IgG; Cell Signaling Technology, Danvers, MA), and total VASP (rabbit, 1:1000, IgG; Cell Signaling Technology) were used. Secondary antibody was used at 1:5000 (rabbit; Cell Signaling Technology). Densitometry was performed using ImageJ software (National Institutes of Health, Bethesda, MD), and the results are expressed as the ratio of the density of analyzed protein to the density of total VASP (de Oliveira et al., 2016).

Statistical Analysis. Data are expressed as the mean \pm S.E.M., and $n$ indicates the number of animals. GraphPad Prism software was used for statistical analysis. One-way analysis of variance followed by the Bonferroni correction was used to analyze the other parameters. The unpaired $t$ test was used when necessary. $P<0.05$ was accepted as significant.

\section{Results}

Concentration-Response Curves to the Nonselective Inhibitor, MK 571, in the Bladder, Prostate, and Urethra. Our first step was to verify whether MK 571 alone would induce any response in the bladder, prostate, and urethra. As shown in Fig. 1, the cumulative addition of MK $571(1-30 \mu \mathrm{M})$ induced only small relaxation responses at $30 \mu \mathrm{M}$ in the bladder $(30 \% \pm 1.5 \%, n=4$; Fig. $1 \mathrm{~A})$, prostate $(20 \% \pm 3.3 \%, n=4$; Fig. $1 \mathrm{~B})$, and urethra $(23 \% \pm 4.8 \%, n=4$; Fig. 1C). Because we proposed to test the possibility that inhibition of MRPs by MK 571 synergizes with substances that accumulate cGMP and cAMP, all of the following assays were carried out using $20 \mu \mathrm{M}$ MK 571. This concentration was chosen based on our preliminary assays, which showed that this was the lowest concentration that potentiated the relaxation response induced by several cGMP- or cAMPincreasing substances in the bladder, prostate, and urethra without interfering with the basal tonus.

MK 571 Potentiated the Relaxation Induced by Substances That Increase Intracellular Levels of cAMP in the Bladder. cAMP accumulation is considered the most important pathway that induces bladder relaxation during the filling phase to store urine (Oger et al., 2007). The nonselective and $\beta 2$-selective adrenoceptors isoprenaline 

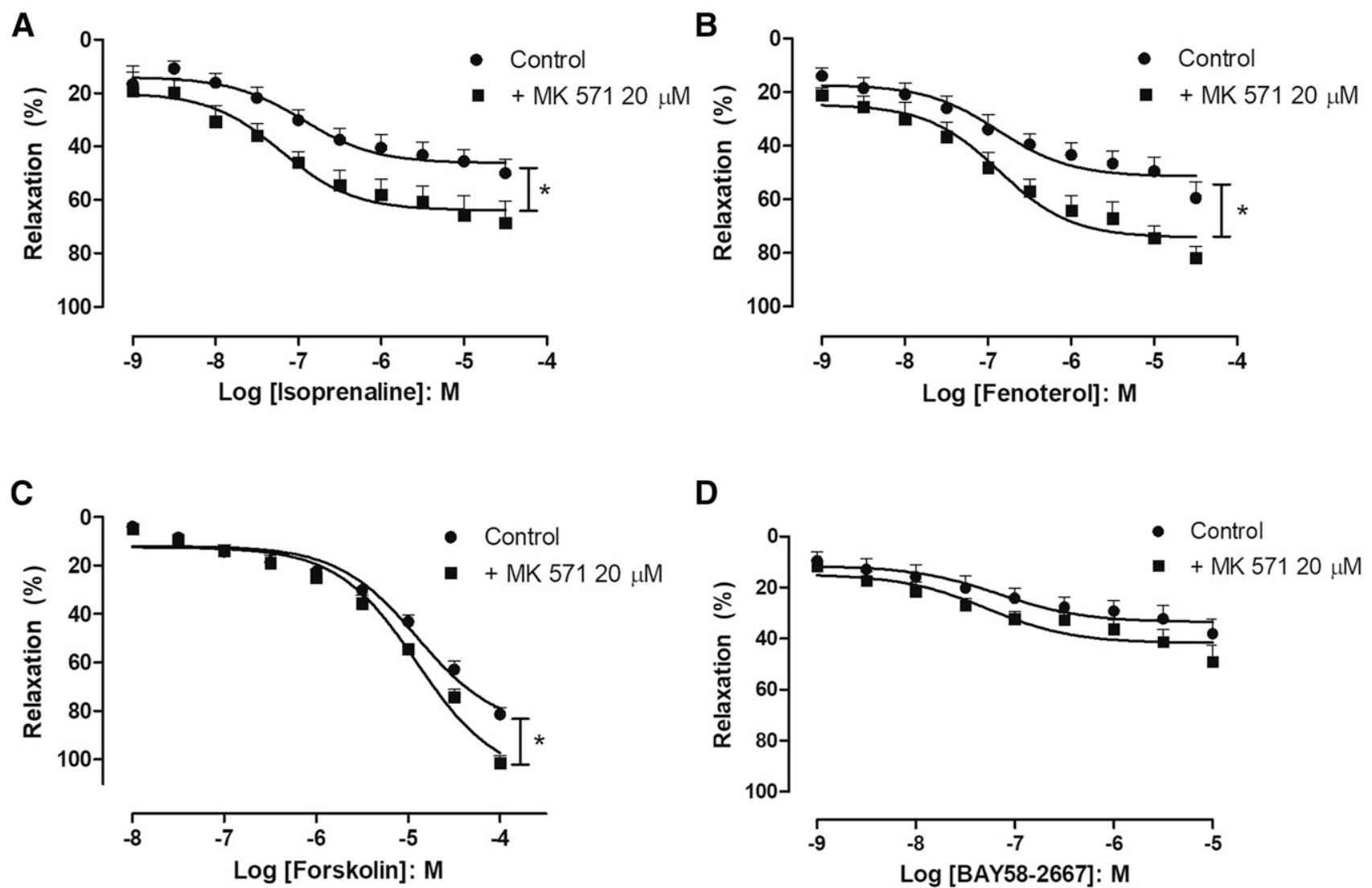

Fig. 2. Effect of MK 571 on relaxation responses induced by cAMP- and cGMP-stimulating substances in the isolated bladder. (A-D) Concentrationresponse curves to isoprenaline $(0.001-100 \mu \mathrm{M} ; \mathrm{A})$, fenoterol $(0.001-100 \mu \mathrm{M} ; \mathrm{B})$, forskolin $(0.01-100 \mu \mathrm{M} ; \mathrm{C})$, and BAY 58-2667 (0.001-10 $\mu \mathrm{M}$; D) in the absence (control) and presence of MK $571(20 \mu \mathrm{M})$ in tissues precontracted with carbachol $(1 \mu \mathrm{M})$. Data are the mean \pm S.E.M. $(n=4$ to 5 animals). $* P<$ 0.05 compared with the control curves.

$(0.001-30 \mu \mathrm{M})$ and fenoterol $(0.001-30 \mu \mathrm{M})$, respectively, induced concentration-dependent relaxation responses with $E_{\max }$ values of $50 \% \pm 5.0 \%(n=5$; Fig. $2 \mathrm{~A})$ and $59 \% \pm 6.1 \%$ ( $n=5$; Fig. 2B). In the presence of MK $571(20 \mu \mathrm{M})$, the $E_{\max }$ value of isoproterenol or fenoterol was increased by approximately $37 \%(P<0.05)$. To rule out that the effect of MK 571 could only be observed with the activation of $\beta$-adrenoceptors, we also tested the effect of the adenylate cyclase activator, forskolin. A $24 \%$ increase in the $E_{\max }$ of forskolin was observed in the presence of MK $571(P<0.05)$ (Fig. 2C).

Accumulation of cGMP also induces smooth muscle relaxation in the bladder, although this effect is more pronounced when substances are given in vivo rather than in vitro (Oger et al., 2010). BAY 58-2667 is a potent sGC activator that induces smooth muscle relaxation. In this study, BAY 58-2667 concentration-dependently relaxed the bladder, with $\mathrm{pEC}_{50}$ and $E_{\max }$ values of $7.16 \% \pm 0.33 \%$ and $38 \% \pm 5.8 \%$ (Fig. 2D), respectively. However, MK 571 did not enhance the relaxation response induced by BAY 58-2667.

Effect of MK 571 on Intracellular Levels of cAMP and p-VASP Ser157 Phosphorylation in Bladders Stimulated with cAMP-Accumulating Substances. Incubation of fenoterol (from $4.6 \pm 0.42$ to $20.3 \pm 3.1 \mathrm{pmol} / \mathrm{ml}$ ) or forskolin (from $4.6 \pm 0.42$ to $28.3 \pm 6.34 \mathrm{pmol} / \mathrm{ml}$ ) in the bladder significantly increased intracellular levels of cAMP above baseline. Preincubation with MK 571 further increased intracellular levels of cAMP by $60 \%$ and $92 \%$, respectively, in tissues stimulated with fenoterol or forskolin (Fig. 3A).
Phosphorylation of VASP at Ser157 (p-VASP Ser157) is an established marker to analyze PKA activity (Joshi et al., 2011). Coincubation of MK $571(20 \mu \mathrm{M})$ with fenoterol increased expression of $\mathrm{p}$-VASP Ser 157 compared with tissues incubated only with fenoterol (Fig. 3B). MK 571 (20 $\mu \mathrm{M})$ when added alone did not enhance cAMP (Fig. 3A) nor did p-VASP 157 levels.

MK 571 Potentiated the Relaxation Induced by cGMP-Accumulating Substances in the Prostate and Urethra. NO released from nitrergic nerve terminals is an important nonadrenergic, noncholinergic neurotransmitter in the LUT organs. The NO-cGMP pathway's contribution to induce prostate or urethral relaxation has been demonstrated in several mammals, including rats (Zarifpour et al., 2015), mice (Alexandre et al., 2014), rabbits, and humans (Calmasini et al., 2016). Therefore, the role of MK $571(20 \mu \mathrm{M})$ in the prostate and urethra was also investigated in the presence of substances that increase intracellular levels of cGMP.

First, we tested an NO donor in the prostate (Fig. 4A) and urethra (Fig. 5A). Sodium nitroprusside concentrationdependently relaxed the prostate $\left(\mathrm{pEC}_{50}=6.94 \% \pm 0.31 \%\right.$, $\left.E_{\max }=31.8 \% \pm 3.16 \%, n=7\right)$ and urethra $\left(\mathrm{pEC}_{50}=6.35 \% \pm\right.$ $0.10 \%, E_{\max } 43.6 \% \pm 4.40 \%, n=5$ ). Preincubation with MK $571(20 \mu \mathrm{M})$ significantly potentiated the relaxation induced by sodium nitroprusside by $70 \%$ and $56 \%(P<0.05)$, respectively.

Second, we tested other substances that also increase cGMP levels in the prostate and urethra. Tadalafil, a PDE5 inhibitor, 
A

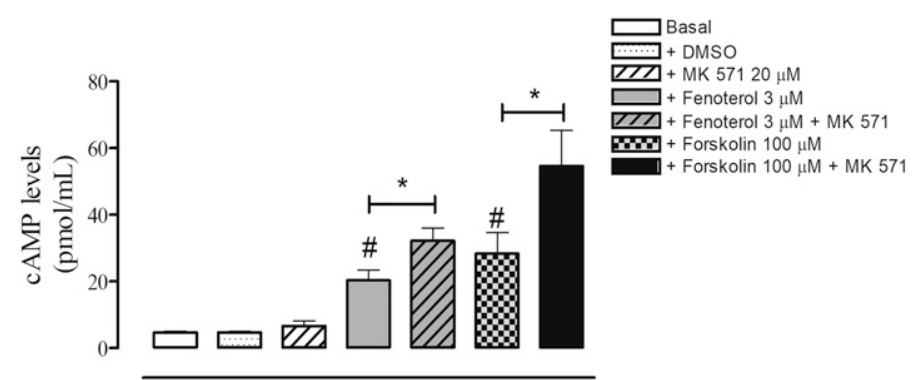

B

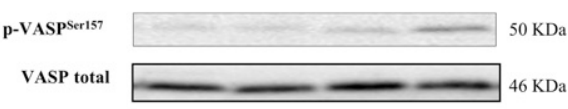

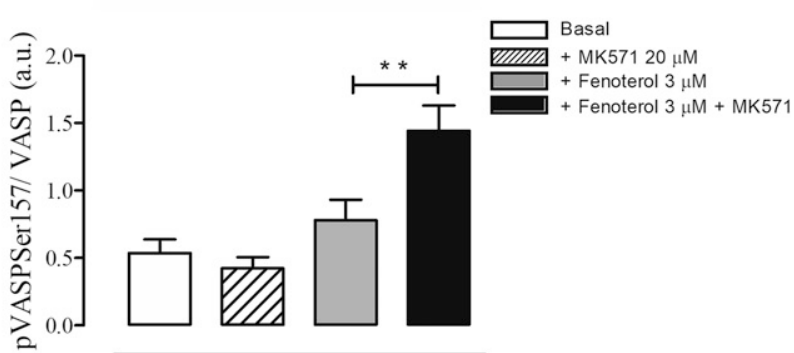

Fig. 3. Intracellular levels of cAMP and p-VASP Ser157 protein expression in the bladder. (A) Intracellular levels of cAMP were determined in unstimulated (basal) tissues and in tissues stimulated with fenoterol $(3 \mu \mathrm{M})$ or forskolin $(100 \mu \mathrm{M})$ in the absence and presence of MK 571 (20 $\mu \mathrm{M})$. Data represent the mean \pm S.E.M. $(n=4-6) .{ }^{*} P<0.05 ;{ }^{\#} P<0.05$ compared with fenoterol/forskolin alone and basal, respectively. (B) Expression of p-VASP Ser157 and total VASP was determined in unstimulated (basal) tissues and tissues stimulated with fenoterol (3 $\mu \mathrm{M})$ alone or in the presence of MK $571(20 \mu \mathrm{M})$. Data are the mean \pm S.E.M. $(n=5-7) . * * P<0.001$ compared with tissues stimulated with fenoterol. DMSO, dimethylsulfoxide.

was approved for use in treating patients with overactive bladder secondary to benign prostatic hyperplasia with or without erectile dysfunction (Giuliano et al., 2013). MK 571 markedly enhanced the relaxation induced by tadalafil by $97 \%$ (Fig. 4B). Our previous study showed that the sGC stimulator, BAY 41-2272, relaxed the urethra in mice; this class of drug could be an interesting option in situations in which the level of NO is reduced (Alexandre et al., 2014). Preincubation with MK 571 markedly increased the $E_{\max }$ values of BAY41-2272 by $46 \%$ (Fig. 5B).
8-Br-cGMP is a cell-permeant cGMP analog with greater resistance to hydrolysis by $\mathrm{PDE}$ than its parent compound, cGMP. Relaxation induced by 8 -Br-cGMP was greatly enhanced in the presence of MK 571 in all studied concentrations in both the prostate (Fig. 4C) and urethra (Fig. 5C), thus reinforcing the functional role of MRPs in these organs to entrap cGMP into cells.

Because substances that increase cAMP also relax the prostate and urethra, we also assessed the role of MK $571(20 \mu \mathrm{M})$ in tissues stimulated with forskolin with or without
A

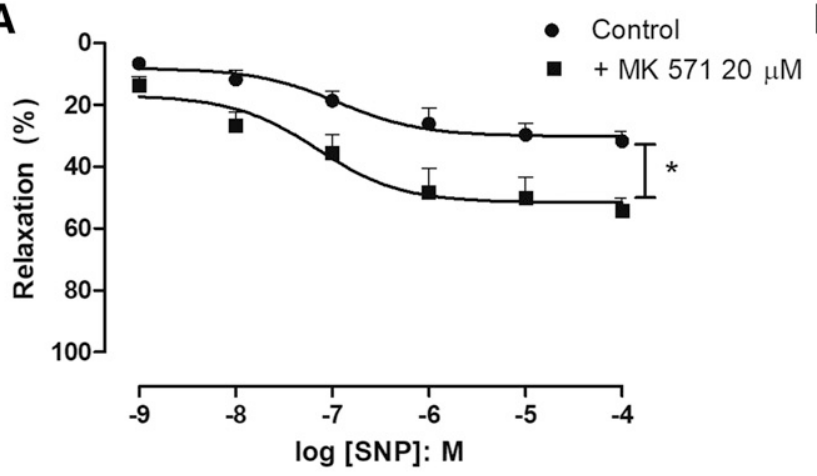

C

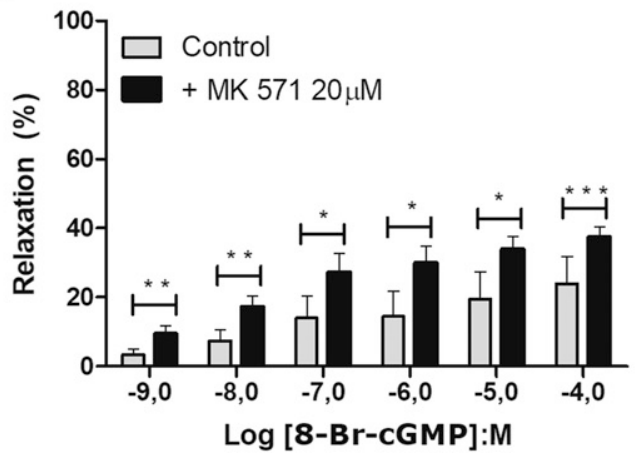

B
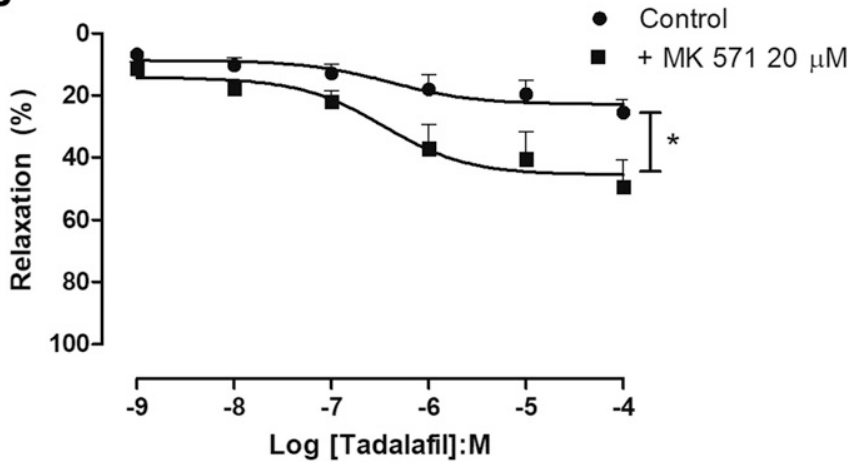

D

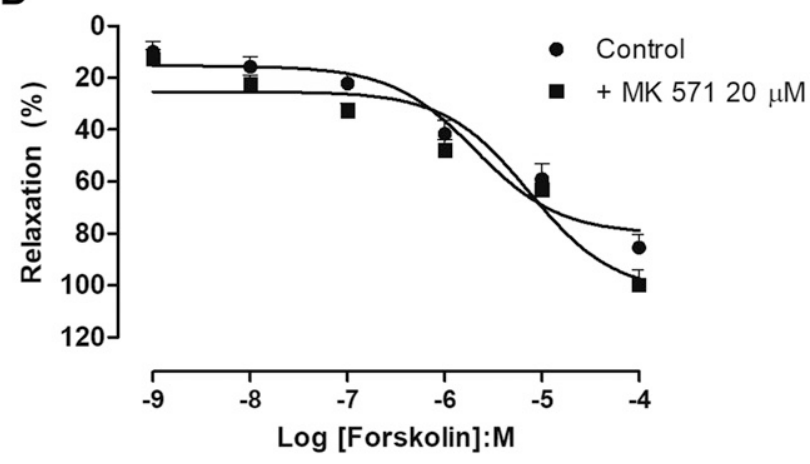

Fig. 4. Effect of MK 571 on relaxation responses induced by cAMP- and cGMP-stimulating substances in the isolated prostate. (A-D) Concentrationresponse curves to sodium nitroprusside $(0.001-100 \mu \mathrm{M} ; \mathrm{A})$, tadalafil $(0.001-100 \mu \mathrm{M} ; \mathrm{B}), 8-\mathrm{Br}$-cGMP $(0.001-100 \mu \mathrm{M}$; C), and forskolin $(0.001-100 \mu \mathrm{M}$; D) in the absence (control) and presence of MK $571(20 \mu \mathrm{M})$ in tissues precontracted with phenylephrine $(10 \mu \mathrm{M})$. Data are the mean \pm S.E.M. $(n=4-7$ animals). $* P<0.05 ; * * P<0.01 ; * * * P<0.001$ compared with the control curves. SNP, sodium nitroprusside. 
A $\quad$ Control

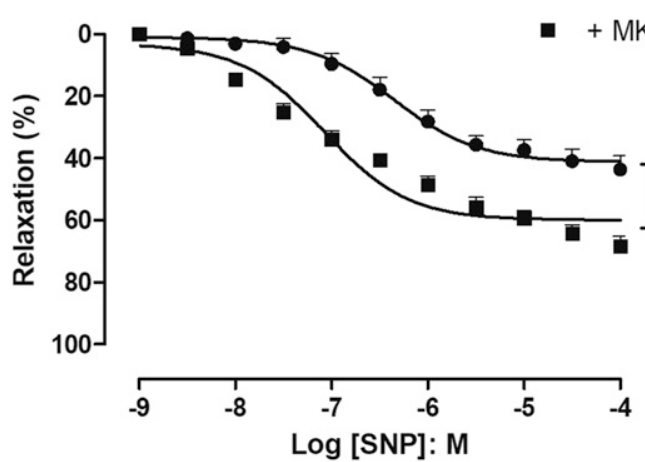

C

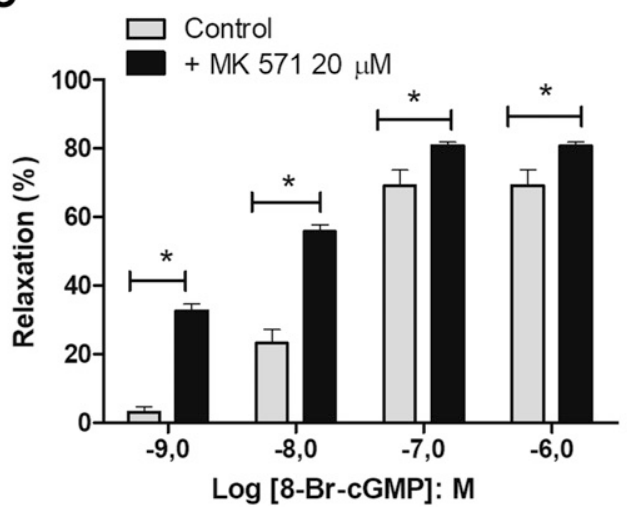

B

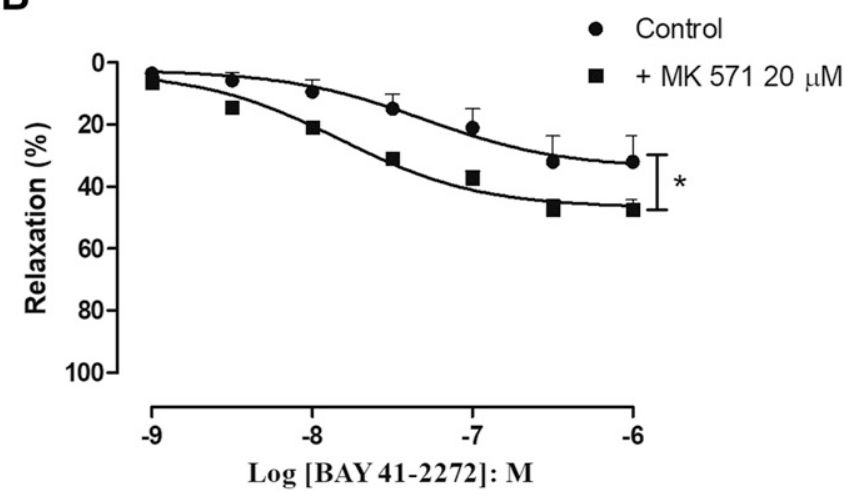

D

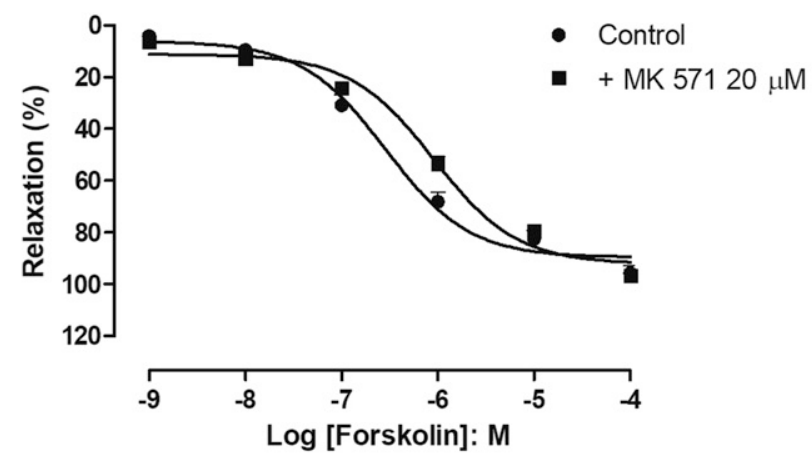

Fig. 5. Effect of MK 571 on relaxation responses induced by cAMP- and cGMP-stimulating substances in the isolated urethra. (A-D) Concentrationresponse curves to sodium nitroprusside (0.001-100 $\mu \mathrm{M}$; A), BAY 41-2272 (0.001-1 $\mu \mathrm{M}$; B), 8-Br-cGMP $(0.001-1 \mu \mathrm{M}$; C), and forskolin (0.001-100 $\mu \mathrm{M}$; D) in the absence (control) and presence of MK $571(20 \mu \mathrm{M})$. Data are the mean \pm S.E.M. $(n=4-6$ animals). $* P<0.05$ compared with the control curves. SNP, sodium nitroprusside.

MK 571. Although forskolin concentration-dependently relaxed the prostate (Fig. 4D) and urethra (Fig. 5D), MK 571 did not significantly affect this response. These results suggest that, at least in the prostate and urethra, inhibition of MRPs seems to not regulate intracellular levels of cAMP.

Effect of MK 571 on Intracellular Levels of cGMP and p-VASP Ser239 Phosphorylation in the Prostate Stimulated with cGMP-Accumulating Substances. MK $571(20 \mu \mathrm{M})$ increased intracellular levels of cGMP by $4-$ and 2 -fold, respectively, in the prostate stimulated with sodium nitroprusside or tadalafil compared with the drugs added alone (Fig. 6A).

Phosphorylation of VASP at Ser239 is an established marker for the analysis of PKG activity in several smooth muscle tissues (Joshi et al., 2011). A 2-fold increase in p-VASP Ser239 was observed in tissues treated with MK 571 plus sodium nitroprusside compared with sodium nitroprusside alone. Neither cGMP levels (Fig. 6A) nor phosphorylation levels (Fig. 6B) were affected when MK 571 was added alone.

\section{Discussion}

Our results clearly show that MK 571 markedly enhanced relaxation induced by substances that increase cAMP or cGMP levels accompanied by greater intracellular levels of these nucleotides, hence activating the p-VASP Ser157 and p-VASP Ser239 signaling pathways in the bladder and prostate/urethra, respectively. Interestingly, $20 \mu \mathrm{M} \mathrm{MK}$
571 alone did not enhance smooth muscle relaxation, implying that MRP function is favored under conditions in which intracellular cyclic nucleotide levels rise.

MK 571 is considered the major pharmacological tool to evaluate the role of MRP4 or MRP5 in controlling cyclic nucleotide levels. MK 571 leads to greater intracellular levels of $\mathrm{cAMP} / \mathrm{cGMP}$ in different cells and tissues such as the intestinal epithelium (Li et al., 2007), pulmonary artery (Hara et al., 2011), platelets (Borgognone and Pulcinelli, 2012), and fibroblasts (Sinha et al., 2013). In hearts from aged rats (Carillion et al., 2015) and in pulmonary arteries from patients with pulmonary hypertension (Hara et al., 2011), MK 571 induced positive chronotropism and vasodilation due to the rise in cAMP and cAMP/cGMP levels, respectively.

MRP4 has a relatively high affinity for both cAMP $(45 \mu \mathrm{M})$ and cGMP $(10 \mu \mathrm{M})$ in membrane vesicles (Kruh and Belinsky, 2003). cAMP and cGMP levels were greater than $\mathrm{MRP}^{+/+}$in mouse embryonic fibroblasts from $\mathrm{MRP}^{-1-}$ mice, leading to increased migration. However, cyclic nucleotide accumulation was even greater in the presence of cAMP- and cGMPstimulating substances such as forskolin and zaprinast, respectively, than in unstimulated cells. In MRP4-overexpressing NIH 3T3 cells transfected with cAMP and cGMP sensors, prior incubation with MK $571(20 \mu \mathrm{M})$ rapidly increased levels of both cAMP and cGMP as detected by Förster resonance energy transfer emission, although the effect of MK 571 was more pronounced on cAMP levels (50\% increase) than cGMP (7\% increase) (Sinha et al., 2013). 
A

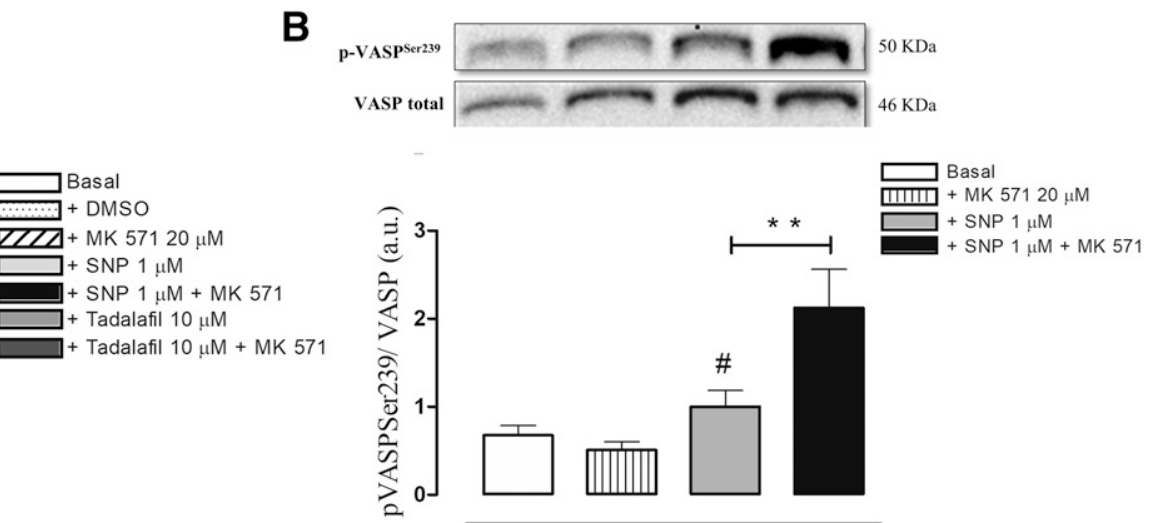

Fig. 6. Intracellular levels of cGMP and p-VASP Ser239 protein expression in the prostate. (A) Intracellular levels of cGMP were determined in unstimulated (basal) tissues and in tissues stimulated with sodium nitroprusside $(1 \mu \mathrm{M})$ or tadalafil (10 $\mu \mathrm{M})$ in the absence and presence of MK $571(20 \mu \mathrm{M})$. Data are the mean \pm S.E.M. $(n=4-7) . * P<0.05$ compared with sodium nitroprusside or tadalafil when added alone. (B) Protein expression of p-VASP Ser239 and total VASP was determined in unstimulated (basal) tissues and tissues stimulated with sodium nitroprusside (1 $\mu \mathrm{M}$ ) alone or in the presence of MK $571(20 \mu \mathrm{M})$. Data are the mean \pm S.E.M. $(n=10-13) .{ }^{* * P} P 0.0001$ compared with tissues stimulated with sodium nitroprusside; ${ }^{\#} P<0.05$ compared with basal levels. DMSO, dimethylsulfoxide; SNP, sodium nitroprusside.

The functional role of MRP5 is less studied than that of MRP4. For instance, the amount of $\left[{ }^{3} \mathrm{H}\right]$-cGMP taken by membrane vesicles in V79 lung Hamster fibroblasts overexpressing human MRP5-cDNA was 4-fold higher than $\left[{ }^{3} \mathrm{H}\right]$ cAMP. The apparent affinity $\left(K_{\mathrm{m}}\right)$ for cGMP was $2.1 \pm 0.2 \mu \mathrm{M}$ compared with $379 \pm 24 \mu \mathrm{M}$ for cAMP, whereas the transport efficiency $\left(V_{\text {max }} / K_{\mathrm{m}}\right)$ was 23 times higher for cGMP, thus suggesting that MRP5 is a physiologic transporter for cGMP (Jedlitschky et al., 2000). Because of the lack of selective pharmacological inhibitors for MRP5, more studies are needed to evaluate whether MRP5 is as important as MRP4 in regulating intracellular levels of cGMP in different cell types.

In the human urogenital tract, MRP4 expression was observed in the plasma membrane of the ureter mucosa, in the basolateral membrane of glandular epithelial cells of the prostate, and in smooth muscle cells of the bladder and corpus cavernosum (Rius et al., 2005). However, Rius et al. (2005) did not evaluate the expression of MRP5. The location of MRP4 in the membrane is cell and tissue specific, implying that substrate transport can occur into the blood and urine or toward adjacent cells into the extracellular matrix.

cAMP/PKA is considered the major pathway that induces relaxation in the bladder of several species, including rats (Werkström et al., 2009), mice (Akakpo et al., 2017), rabbit (Qiu et al., 2002), and humans (Hayashi et al., 2016). Sevenday treatment with the adenylate cyclase activator, colforsin, normalized cystometric parameters and reversed and restored protein expression of phosphorylated myosin phosphatase target subunit 1, which is involved in smooth muscle contraction, in mice lacking the $S$-nitrosoglutathione reductase enzyme (which presented greater voiding and nonvoiding contraction frequencies compared with the wild type). These results led Akakpo et al. (2017) to conclude that cAMP reversed the bladder dysfunction seen in this animal model. No alterations in the protein expression of phosphorylated endothelial or neuronal nitric oxide synthase were observed in colforsin-treated animals (Akakpo et al., 2017). To date, the $\beta 3$-adrenoceptor agonist mirabegron is the newest therapeutic option for treating patients with overactive bladder, with fewer side effects than antimuscarinic therapy (Staskin et al., 2018). Therefore, we focused the majority of our analysis on the role of MK 571 in the presence of substances that increase cAMP. Whereas $20 \mu \mathrm{M}$ MK 571 produced only small relaxation responses and did not enhance basal levels of cAMP or p-VASP Ser157, a marked increase in relaxation, accompanied by enhanced levels of cAMP and p-VASP Ser 157 above baseline, was observed in the presence of cAMP-accumulating substances such as isoproterenol, fenoterol, and forskolin. Another interesting finding was that relaxation induced by the stable analog of cAMP (8-Br-cAMP) was enhanced in the presence of MK 571, thus reinforcing the physiologic role of MRP4 to entrap cAMP.

Impairment of the NO signaling pathway has been shown to contribute to detrusor hyperactivity, since chronic inhibition by the nonselective NO inhibitor, $N$-nitroarginine methyl ester (Mónica et al., 2008), or deletion of the neuronal nitric oxide synthase gene led to detrusor overactivity or hypertrophic bladder and reduced urethral smooth muscle relaxation (Burnett et al., 1997). However, when substances that increase intracellular levels of cGMP (e.g., sodium nitroprusside or sildenafil) were added in vitro only, small relaxation responses (approximately 20\%-40\%) were observed at high concentrations (above $10 \mu \mathrm{M}$ ) in the bladder of rats (Morelli et al., 2009) and humans (Fusco et al., 2012). On the other hand, a marked improvement in bladder function was observed when tadalafil (Minagawa et al., 2012) or sGC modulators (Mónica et al., 2011; Leiria et al., 2014) were given chronically to rats (Nomiya et al., 2013). More studies are needed to determine whether improvement in the overactive bladder under chronically cGMP-increasing substances is due to a direct effect on the smooth muscle or vascular bed, a decrease in afferent fiber firing, or relaxation of the bladder outlet. In our study, MK 571 did not enhance BAY 58-2667-induced relaxation, thus suggesting that MRPs do not seem to control cGMP intracellular levels under physiologic conditions.

NO released from nitrergic nerves is an important neurotransmitter in the LUT that stimulates sGC to accumulate cGMP to induce relaxation in the urethra (Friebe and Koesling, 2003), prostate (Calmasini et al., 2016), and corpus cavernosum (Mills et al., 2001). However, the role of NO as an inhibitory mediator in the outflow region of the LUT is well 
established in urethral tissue from dogs (Takeda and Lepor, 1995), pigs and humans (Werkström et al., 2006), rabbits (Lyons et al., 2007), and mice (Lagou et al., 2006). MK 571 amplified the relaxation response induced by sodium nitroprusside or tadalafil in the prostate, accompanied by greater levels of cGMP, but did not affect the response induced by forskolin. Similar results were observed in the urethra. Our findings corroborate those of a previous study carried out in the corpus cavernosum of Swiss mice, in which MK $571(10 \mu \mathrm{M})$ increased relaxation responses induced by acetylcholine, transmural stimulation, sodium nitroprusside, and sildenafil but did not enhance the relaxation induced by forskolin or pinacidil, an ATP-potassium channel opener (Boydens et al., 2017).

In conclusion, our results strongly support that the inhibition of MRPs by MK 571 significantly augments intracellular levels of cAMP or cGMP in the bladder, prostate, and urethra only in the presence of cAMP- and cGMP-increasing substances. Our study paves the way for further investigation of whether these transporters are involved in urogenital tract disorders, as lower intracellular levels of cAMP or cGMP are related to and contribute to LUT symptoms secondary to benign prostatic hyperplasia.

\section{Authorship Contributions}

Participated in research design: Bertollotto, de Oliveira, Alexandre, Calmasini, Antunes, Mónica.

Conducted experiments: Bertollotto, de Oliveira, Alexandre, Passos.

Contributed new reagents or analytic tools: Antunes, Mónica.

Performed data analysis: Bertollotto, de Oliveira, Alexandre, Mónica.

Wrote or contributed to the writing of the manuscript: Bertollotto, Mónica.

\section{References}

Ahloulay M, Déchaux M, Hassler C, Bouby N, and Bankir L (1996) Cyclic AMP is a hepatorenal link influencing natriuresis and contributing to glucagon-induced hyperfiltration in rats. J Clin Invest 98:2251-2258.

Akakpo W, Musicki B, and Burnett AL (2017) cAMP-dependent regulation of RhoA/ Rho-kinase attenuates detrusor overactivity in a novel mouse experimental model. BJU Int 120:143-151.

Alexandre EC, Leiria LO, Silva FH, Mendes-Silvério CB, Calmasini FB, Davel AP Mónica FZ, De Nucci G, and Antunes E (2014) Soluble guanylyl cyclase (sGC) degradation and impairment of nitric oxide-mediated responses in urethra from obese mice: reversal by the sGC activator BAY 60-2770. J Pharmacol Exp Ther 349:2-9.

Borgognone A and Pulcinelli FM (2012) Reduction of cAMP and cGMP inhibitory effects in human platelets by MRP4-mediated transport. Thromb Haemost 108 955-962.

Boydens C, Pauwels B, Vanden Daele L, and Van de Voorde J (2017) Inhibition of cyclic GMP export by multidrug resistance protein 4: a new strategy to treat erectile dysfunction? J Sex Med 14:502-509.

Burnett AL, Calvin DC, Chamness SL, Liu JX, Nelson RJ, Klein SL, Dawson VL, Dawson TM, and Snyder SH (1997) Urinary bladder-urethral sphincter dysfunction in mice with targeted disruption of neuronal nitric oxide synthase models idiopathic voiding disorders in humans. Nat Med 3:571-574.

Calmasini FB, Alexandre EC, Silva FH, De Nucci G, Antunes E, D'Ancona CA, and Mónica FZ (2016) Soluble guanylate cyclase modulators, BAY 41-2272 and BAY 60-2770, inhibit human and rabbit prostate contractility. Urology 94:312 e9-312.e15.

Calmasini FB, de Oliveira MG, Alexandre EC, da Silva FH, da Silva CPV, Candido TZ, Antunes E, and Mónica FZ (2017) Long-term treatment with the beta-3 adrenoceptor agonist, mirabegron ameliorates detrusor overactivity and restores cyclic adenosine monophosphate (cAMP) levels in obese mice. Neurourol Urodyn 36:1511-1518

Carillion A, Feldman S, Jiang C, Atassi F, Na N, Mougenot N, Besse S, Hulot JS, Riou B, and Amour J (2015) Overexpression of cyclic adenosine monophosphate effluent protein MRP4 induces an altered response to $\beta$-adrenergic stimulation in the senescent rat heart. Anesthesiology 122:334-342.

Chan P and Lutfy K (2016) Molecular changes in opioid addiction: the role of adenylyl cyclase and cAMP/PKA system. Prog Mol Biol Transl Sci 137:203-227.

Chen ZS, Lee K, and Kruh GD (2001) Transport of cyclic nucleotides and estradiol 17-beta-D-glucuronide by multidrug resistance protein 4 . Resistance to 6-mercaptopurine and 6-thioguanine. J Biol Chem 276:33747-33754. de Oliveira MG, Calmasini FB, Alexandre EC, De Nucci G, Mónica FZ, and Antunes E (2016) Activation of soluble guanylyl cyclase by BAY 58-2667 improves bladder function in cyclophosphamide-induced cystitis in mice. Am J Physiol Renal Physiol 311:F85-F93.

Decouture B, Dreano E, Belleville-Rolland T, Kuci O, Dizier B, Bazaa A, Coqueran B, Lompre AM, Denis CV, Hulot JS, et al. (2015) Impaired platelet activation and cAMP homeostasis in MRP4-deficient mice. Blood 126:1823-1830.

Fraser MO and Chancellor MB (2003) Neural control of the urethra and development of pharmacotherapy for stress urinary incontinence. BJU Int 91:743-748.

Friebe A and Koesling D (2003) Regulation of nitric oxide-sensitive guanylyl cyclase. Circ Res 93:96-105.

Fusco F, di Villa Bianca Rd, Mitidieri E, Cirino G, Sorrentino R, and Mirone V (2012) Sildenafil effect on the human bladder involves the L-cysteine/hydrogen sulfide pathway: a novel mechanism of action of phosphodiesterase type 5 inhibitors. Eur Urol 62:1174-1180.

Garg UC and Hassid A (1989) Nitric oxide-generating vasodilators and 8-bromocyclic guanosine monophosphate inhibit mitogenesis and proliferation of cultured rat vascular smooth muscle cells. J Clin Invest 83:1774-1777.

Giuliano F, Ückert S, Maggi M, Birder L, Kissel J, and Viktrup L (2013) The mechanism of action of phosphodiesterase type 5 inhibitors in the treatment of lower urinary tract symptoms related to benign prostatic hyperplasia. Eur Urol 63: $506-516$

Hara Y, Sassi Y, Guibert C, Gambaryan N, Dorfmüller P, Eddahibi S, Lompré AM, Humbert M, and Hulot JS (2011) Inhibition of MRP4 prevents and reverses pulmonary hypertension in mice. J Clin Invest 121:2888-2897.

Hayashi K, Fukagai T, Koshikiya A, Igarashi A, Morita M, Sasaki H, and Ishikawa K (2016) Effect of tadalafil that was additionally administered to patients receiving an alpha1-blocker in japanese men with lower urinary tract symptoms suggestive of benign prostatic hyperplasia. Nippon Hinyokika Gakkai Zasshi 107:28-33.

Jedlitschky G, Burchell B, and Keppler D (2000) The multidrug resistance protein 5 functions as an ATP-dependent export pump for cyclic nucleotides. J Biol Chem 275:30069-30074.

Joshi CN, Martin DN, Fox JC, Mendelev NN, Brown TA, and Tulis DA (2011) The soluble guanylate cyclase stimulator BAY 41-2272 inhibits vascular smooth muscle growth through the cAMP-dependent protein kinase and cGMP-dependent protein kinase pathways. J Pharmacol Exp Ther 339:394-402.

Kedia GT, Uckert S, Kedia M, and Kuczyk MA (2009) Effects of phosphodiesterase inhibitors on contraction induced by endothelin-1 of isolated human prostatic tissue. Urology 73:1397-1401.

Krawutschke C, Koesling D, and Russwurm M (2015) Cyclic GMP in vascular relaxation: export is of similar importance as degradation. Arterioscler Thromb Vasc Biol 35:2011-2019.

Kruh GD and Belinsky MG (2003) The MRP family of drug efflux pumps. Oncogene 22:7537-7552.

Köck K, Grube M, Jedlitschky G, Oevermann L, Siegmund W, Ritter CA, and Kroemer HK (2007) Expression of adenosine triphosphate-binding cassette (ABC) drug transporters in peripheral blood cells: relevance for physiology and pharmacotherapy Clin Pharmacokinet 46:449-470.

Lagou M, Drake MJ, Markerink-VAN Ittersum M, DE Vente J, and Gillespie JI (2006) Interstitial cells and phasic activity in the isolated mouse bladder. BJU Int 98:643-650.

Leiria LO, Silva FH, Davel AP, Alexandre EC, Calixto MC, De Nucci G, Mónica FZ, and Antunes E (2014) The soluble guanylyl cyclase activator BAY 60-2770 ameliorates overactive bladder in obese mice. J Urol 191:539-547.

Li C, Krishnamurthy PC, Penmatsa H, Marrs KL, Wang XQ, Zaccolo M, Jalink K, Li M, Nelson DJ, Schuetz JD, et al. (2007) Spatiotemporal coupling of cAMP transporter to CFTR chloride channel function in the gut epithelia. Cell 131:940-951.

Lyons AD, Gardiner TA, and McCloskey KD (2007) Kit-positive interstitial cells in the rabbit urethra: structural relationships with nerves and smooth muscle. BJU Int 99:687-694

McVary KT, Roehrborn CG, Kaminetsky JC, Auerbach SM, Wachs B, Young JM Esler A, Sides GD, and Denes BS (2007) Tadalafil relieves lower urinary tract symptoms secondary to benign prostatic hyperplasia. J Urol 177:1401-1407.

Mellion BT, Ignarro LJ, Ohlstein EH, Pontecorvo EG, Hyman AL, and Kadowitz PJ (1981) Evidence for the inhibitory role of guanosine 3', 5'-monophosphate in ADPinduced human platelet aggregation in the presence of nitric oxide and related vasodilators. Blood 57:946-955.

Merrill L, Gonzalez EJ, Girard BM, and Vizzard MA (2016) Receptors, channels, and signalling in the urothelial sensory system in the bladder. Nat Rev Urol 13: 193-204.

Mills TM, Chitaley K, and Lewis RW (2001) Vasoconstrictors in erectile physiology. Int J Impot Res 13 (Suppl 5):S29-S34.

Minagawa T, Aizawa N, Igawa Y, and Wyndaele JJ (2012) Inhibitory effects of phosphodiesterase 5 inhibitor, tadalafil, on mechanosensitive bladder afferent nerve activities of the rat, and on acrolein-induced hyperactivity of these nerves. $B J U$ Int 110 (Pt B):E259-E266.

Mónica FZ and Antunes E (2018) Stimulators and activators of soluble guanylate cyclase for urogenital disorders. Nat Rev Urol 15:42-54.

Mónica FZ, Bricola AA, Báu FR, Freitas LL, Teixeira SA, Muscará MN, Abdalla FM, Porto CS, De Nucci G, Zanesco A, et al. (2008) Long-term nitric oxide deficiency causes muscarinic supersensitivity and reduces beta(3)-adrenoceptor-mediated relaxation, causing rat detrusor overactivity. $\mathrm{Br}$ J Pharmacol 153:1659-1668.

Mónica FZ, Reges R, Cohen D, Silva FH, De Nucci G, D'Ancona CA, and Antunes E (2011) Long-term administration of BAY 41-2272 prevents bladder dysfunction in nitric oxide-deficient rats. Neurourol Urodyn 30:456-460.

Moon C, Zhang W, Ren A, Arora K, Sinha C, Yarlagadda S, Woodrooffe K, Schuetz JD, Valasani KR, de Jonge HR, et al. (2015) Compartmentalized accumulation of cAMP near complexes of multidrug resistance protein 4 (MRP4) and cystic fibrosis transmembrane conductance regulator (CFTR) contributes to drug-induced diarrhea. J Biol Chem 290:11246-11257. 
Morelli A, Filippi S, Sandner P, Fibbi B, Chavalmane AK, Silvestrini E, Sarchielli E, Vignozzi L, Gacci M, Carini M, et al. (2009) Vardenafil modulates bladder contractility through cGMP-mediated inhibition of RhoA/Rho kinase signaling pathway in spontaneously hypertensive rats. J Sex Med 6:1594-1608.

Nomiya M, Burmeister DM, Sawada N, Campeau L, Zarifpour M, Keys T, Peyton C, Yamaguchi O, and Andersson KE (2013) Prophylactic effect of tadalafil on bladder function in a rat model of chronic bladder ischemia. $J$ Urol 189:754-761.

Oger S, Behr-Roussel D, Gorny D, Denys P, Lebret T, Alexandre L, and Giuliano F (2007) Relaxation of phasic contractile activity of human detrusor strips by cyclic nucleotide phosphodiesterase type 4 inhibition. Eur Urol 51:772-780, discussion $780-781$.

Oger S, Behr-Roussel D, Gorny D, Lebret T, Validire P, Cathelineau X, Alexandre L, and Giuliano F (2010) Signalling pathways involved in sildenafil-induced relaxation of human bladder dome smooth muscle. Br J Pharmacol 160:1135-1143.

Pyriochou A and Papapetropoulos A (2005) Soluble guanylyl cyclase: more secrets revealed. Cell Signal 17:407-413.

Qiu Y, Kraft P, Craig EC, Liu X, and Haynes-Johnson D (2002) Cyclic nucleotide phosphodiesterases in rabbit detrusor smooth muscle. Urology 59:145-149.

Rahnama'i MS, Ückert S, Hohnen R, and van Koeveringe GA (2013) The role of phosphodiesterases in bladder pathophysiology. Nat Rev Urol 10:414-424.

Reid G, Wielinga P, Zelcer N, van der Heijden I, Kuil A, de Haas M, Wijnholds J, and Borst $\mathrm{P}$ (2003) The human multidrug resistance protein MRP4 functions as a prostaglandin efflux transporter and is inhibited by nonsteroidal antiinflammatory drugs. Proc Natl Acad Sci USA 100:9244-9249.

Ritter CA, Jedlitschky G, Meyer zu Schwabedissen H, Grube M, Köck K, and Kroemer HK (2005) Cellular export of drugs and signaling molecules by the ATP-binding cassette transporters MRP4 (ABCC4) and MRP5 (ABCC5). Drug Metab Rev 37:253-278.

Rius M, Thon WF, Keppler D, and Nies AT (2005) Prostanoid transport by multidrug resistance protein 4 (MRP4/ABCC4) localized in tissues of the human urogenital tract. J Urol 174:2409-2414.

Sager G and Ravna AW (2009) Cellular efflux of cAMP and cGMP - a question about selectivity. Mini Rev Med Chem 9:1009-1013.

Sancho M, Ferrero JJ, Triguero D, Torres M, and Garcia-Pascual A (2014) Altered neuronal and endothelial nitric oxide synthase expression in the bladder and urethra of cyclophosphamide-treated rats. Nitric Oxide 39:8-19.

Sassi Y, Lipskaia L, Vandecasteele G, Nikolaev VO, Hatem SN, Cohen Aubart F, Russel FG, Mougenot N, Vrignaud C, Lechat P, et al. (2008) Multidrug resistanceassociated protein 4 regulates cAMP-dependent signaling pathways and controls human and rat SMC proliferation. J Clin Invest 118:2747-2757.

Sinha C, Ren A, Arora K, Moon CS, Yarlagadda S, Zhang W, Cheepala SB, Schuetz JD, and Naren AP (2013) Multi-drug resistance protein 4 (MRP4)-mediated regulation of fibroblast cell migration reflects a dichotomous role of intracellular cyclic nucleotides. J Biol Chem 288:3786-3794.

Staskin D, Herschorn S, Fialkov J, Tu LM, Walsh T, and Schermer CR (2018) A prospective, double-blind, randomized, two-period crossover, multicenter study to evaluate tolerability and patient preference between mirabegron and tolterodine in patients with overactive bladder (PREFER study). Int Urogynecol J Pelvic Floor Dysfunct 29:273-283.
Takeda M and Lepor H (1995) Nitric oxide synthase in dog urethra: a histochemical and pharmacological analysis. $\mathrm{Br}$ J Pharmacol 116:2517-2523.

Tanaka M, Abe K, Oka M, Saku K, Yoshida K, Ishikawa T, McMurtry IF, Sunagawa K, Hoka S, and Tsutsui H (2017) Inhibition of nitric oxide synthase unmasks vigorous vasoconstriction in established pulmonary arterial hypertension. Physiol Rep 5:e13537.

Uckert S, Hedlund P, Andersson KE, Truss MC, Jonas U, and Stief CG (2006) Update on phosphodiesterase (PDE) isoenzymes as pharmacologic targets in urology: present and future. Eur Urol 50:1194-1207, discussion 1207.

Uckert S, Stief CG, Mayer M, Jonas U, and Hedlund P (2005) Distribution and functional significance of phosphodiesterase isoenzymes in the human lower urinary tract. World $J$ Urol 23:368-373.

Vaandrager AB, Bot AG, Ruth P, Pfeifer A, Hofmann F, and De Jonge HR (2000) Differential role of cyclic GMP-dependent protein kinase II in ion transport in murine small intestine and colon. Gastroenterology 118:108-114.

Wen J, Luo J, Huang W, Tang J, Zhou H, and Zhang W (2015) The pharmacological and physiological role of multidrug-resistant protein 4. J Pharmacol Exp Ther 354:358-375.

Werkström V, Hedlund P, Lee T, and Andersson KE (2009) Vardenafil-induced relaxation and cyclic nucleotide levels in normal and obstructed rat urinary bladder. BJU Int 104:1740-1745.

Werkström V, Svensson A, Andersson KE, and Hedlund P (2006) Phosphodiesterase 5 in the female pig and human urethra: morphological and functional aspects. $B J U$ Int 98:414-423.

White CW, Xie JH, and Ventura S (2013) Age-related changes in the innervation of the prostate gland: implications for prostate cancer initiation and progression. Organogenesis 9:206-215.

Wu CP, Klokouzas A, Hladky SB, Ambudkar SV, and Barrand MA (2005) Interactions of mefloquine with ABC proteins, MRP1 (ABCC1) and MRP4 (ABCC4) that are present in human red cell membranes. Biochem Pharmacol 70:500-510.

Yamaguchi O, Marui E, Kakizaki H, Homma Y, Igawa Y, Takeda M, Nishizawa O, Gotoh M, Yoshida M, Yokoyama O, et al. (2014) Phase III, randomised, doubleblind, placebo-controlled study of the $\beta 3$-adrenoceptor agonist mirabegron, $50 \mathrm{mg}$ once daily, in Japanese patients with overactive bladder. BJU Int 113:951-960.

Yunes R, Fernández P, Doncel GF, and Acosta AA (2005) Cyclic nucleotide phosphodiesterase inhibition increases tyrosine phosphorylation and hyper motility in normal and pathological human spermatozoa. Biocell 29:287-293.

Zarifpour M, Nomiya M, Sawada N, and Andersson KE (2015) Protective effect of tadalafil on the functional and structural changes of the rat ventral prostate caused by chronic pelvic ischemia. Prostate 75:233-241.

Zhao C, Kim SH, Lee SW, Jeon JH, Kang KK, Choi SB, and Park JK (2011) Activity of phosphodiesterase type 5 inhibitors in patients with lower urinary tract symptoms due to benign prostatic hyperplasia. BJU Int 107:1943-1947.

Address correspondence to: Dr. Fabiola Zakia Mónica, Department of Pharmacology, Faculty of Medical Sciences, University of Campinas, Rua Alexander Fleming, Campinas, SP 13083-881, Brazil. E-mail: fabiolataufic@ gmail.com or fzm@fcm.unicamp.br 